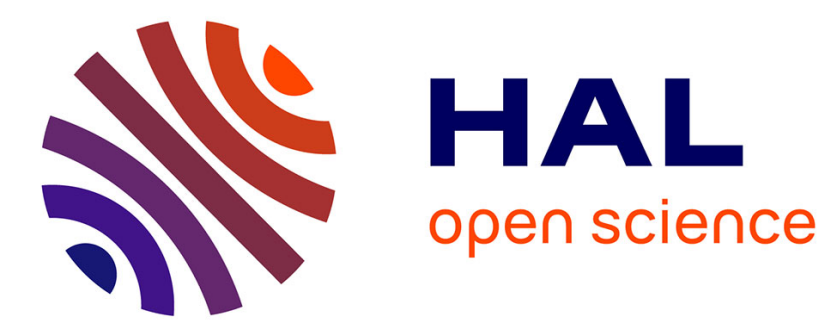

\title{
Electrical characterization of as-grown, annealed and indium-doped Hg1-xZnxTe for x near 0.15
}

\author{
S. Rolland, A. Lasbley, A. Seyni, R. Granger, R. Triboulet
}

\section{To cite this version:}

S. Rolland, A. Lasbley, A. Seyni, R. Granger, R. Triboulet. Electrical characterization of as-grown, annealed and indium-doped Hg1-xZnxTe for x near 0.15. Revue de Physique Appliquée, 1989, 24 (8), pp.795-802. 10.1051/rphysap:01989002408079500 . jpa-00246102

\section{HAL Id: jpa-00246102 https://hal.science/jpa-00246102}

Submitted on 1 Jan 1989

HAL is a multi-disciplinary open access archive for the deposit and dissemination of scientific research documents, whether they are published or not. The documents may come from teaching and research institutions in France or abroad, or from public or private research centers.
L'archive ouverte pluridisciplinaire HAL, est destinée au dépôt et à la diffusion de documents scientifiques de niveau recherche, publiés ou non, émanant des établissements d'enseignement et de recherche français ou étrangers, des laboratoires publics ou privés. 


\title{
Electrical characterization of as-grown, annealed and indium-doped $\mathrm{Hg}_{1-x} \mathrm{Zn}_{x}$ Te for $x$ near 0.15
}

\author{
S. Rolland ( $\left.{ }^{1}\right)$, A. Lasbley ( $\left.{ }^{1}\right)$, A. Seyni ( $\left.{ }^{1}\right)$, R. Granger ( $\left.{ }^{1}\right)$ and R. Triboulet ( ${ }^{2}$ ) \\ (1) I.N.S.A., Laboratoire de Physique des Solides, UA 040786 au C.N.R.S., F-35043 Rennes Cedex, France \\ (2) Laboratoire de Physique des Solides, LP 001332 au C.N.R.S., F-92195 Meudon Cedex, France
}

(Reçu le 27 février 1989, accepté le 17 avril 1989)

\begin{abstract}
Résumé. - Les concentrations et mobilités des porteurs dans $\mathrm{Hg}_{1-x} \mathrm{Zn}_{x} \mathrm{Te}$ pour $x$ voisin de 0,15 sont données pour les matériaux bruts de tirage T.H.M. et après des recuits sous pression de mercure. Ces concentrations et mobilités sont voisines de celles trouvées dans $\mathrm{Hg}_{1-x} \mathrm{Cd}_{x} \mathrm{Te}$ de même largeur de bande interdite $(x=0,22)$. Cependant le coefficient de diffusion du mercure est bien plus faible, ce qui rend plus difficile l'obtention d'échantillons homogènes de type $\mathrm{n}$ par recuit stœchiométrique à basse température, mais traduit une meilleure stabilité du matériau. L'indium est donneur mais a aussi un faible coefficient de diffusion; de plus ce dopage diminue fortement la mobilité des électrons. Il est possible de décrire raisonnablement la mobilité des porteurs et la concentration intrinsèque en utilisant un modèle de Kane pour la bande de conduction. Ce modèle conduit à une estimation de la masse effective des trous lourds voisine de $0,6 m_{0}$.
\end{abstract}

\begin{abstract}
Concentration and mobility of carriers in $\mathrm{Hg}_{1-x} \mathrm{Zn}_{x} \mathrm{Te}$ for $x$ near 0.15 are presented for as grown T.H.M. material and after annealings under mercury pressure. These concentrations and mobilities are near those found in $\mathrm{Hg}_{1-x} \mathrm{Cd}_{x} \mathrm{Te}$ for a same band gap $(x=0.22)$. However the mercury diffusion coefficient is lower, this involves difficulty to obtain homogeneous n-type samples through low temperature stoichiometric annealing but reveales a better stability of the material. Indium is a donor dopant but with also a low diffusion coefficient; moreover this doping strongly decreases the electron mobility. Carrier mobility and intrinsic concentration can be well described with a Kane model for the conduction band. This model leads to an estimation for the heavy hole effective mass of $0.6 \mathrm{~m}_{0}$.
\end{abstract}

\section{Introduction.}

Since a few years, $\mathrm{Hg}_{1-x} \mathrm{Zn}_{x} \mathrm{Te}(\mathrm{MZT})$ appears as an alternative material to $\mathrm{Hg}_{1-x} \mathrm{Cd}_{x} \mathrm{Te}(\mathrm{MCT})$ due to the lack of stability in this last semiconductor, especially for $\mathrm{Hg}$-rich solid solutions used in detectors in the $10 \mu \mathrm{m}$ wavelength range. First theoretical $[1,2]$ and experimental [3-6] studies revealed a better stability and lower composition fluctuations in MZT materials. Infrared detectors in the $8-12 \mu \mathrm{m}$ range have been made using the process technology already used in MCT [7, 8]. In spite of non optimized conditions, these detectors have got performances comparable to MCT ones. Moreover devices lifetime is improved under high temperature tests, confirming a better stability of MZT [8].

A good knowledge of conditions giving definited samples (type, concentration, mobility) is now necessary for device processing optimization.

In this paper we present first detailed analysis of treatments for carrier concentration adjustements either by equilibrium of native defects or by doping with some impurities.

In section 2 we describe experimental processes in order to obtain homogeneous samples with well defined type and carrier concentrations. This is obtained by adjustment of sample temperature and mercury partial vapor pressure. Experimental techniques for electrical measurements are also presented. In section 3 experimental results and the method used to deduce carrier concentrations and mobilities of p-type samples in the mixed conduction range are reported. In section $4, \mathrm{p}$ to $\mathrm{n}$ type conversion which is essential for devices applications is presented. This is obtained from stoechiometric annealing at low temperature and from indium doping through vapor transfert. In section 5 mobility and carrier concentrations are discussed in the framework of the Kane model. 


\section{Experimental processes.}

2.1 ANNEALING TREATMENTS. - Ingots with composition $x$ near 0.15 are grown by the Travelling Heater Method (THM) [3, 6, 9]. Circular slices of $15 \mathrm{~mm}$ diameter and $1 \mathrm{~mm}$ thickness are then cut with a wire saw. Prior to anneals or electrical measurements samples are cleaned in trichlorethylene, rinsed and chemically etched in methanol-Br $(2 \%)$ at room temperature, then rinsed a new time [5].

Annealing treatments are performed in a two temperatures furnace. Samples are placed in cleaned quartz ampoules evacuated at $10^{-5} \mathrm{~Pa}$ of argon at temperature $T_{1}$, and mercury at temperature $T_{2}$ lower than $T_{1} . T_{2}$ controls the partial pressure of mercury. High temperature annealings correspond to $T_{1}=400^{\circ} \mathrm{C} \quad\left(T_{2}=380^{\circ} \mathrm{C}\right)$ and $T_{1}=500^{\circ} \mathrm{C}$ $\left(T_{2}=460^{\circ} \mathrm{C}\right.$ or $\left.350^{\circ} \mathrm{C}\right)$. After each anneal, samples are rapidly air or water quenched. In these conditions, as shown in the next part, samples are ptype. Annealing times were verified to be sufficient to obtain homogeneous samples. Such anneals allow adjustement of carrier concentration but also eliminate tellurium precipitates occuring during the THM growth with tellurium solvent [2].

Low temperature annealings were made at $T_{1}=260^{\circ} \mathrm{C}$ and $T_{2}=240^{\circ} \mathrm{C}$ as usual in MCT in order to obtain n-type samples. The kinetics of the $p$ to n-type conversion is very sensitive to anterior annealings.

Indium vapor phase doping has been also performed at $T_{1}=500^{\circ} \mathrm{C}$ putting a $\operatorname{In}_{y} \mathrm{Hg}_{1-y}$ alloy with adjusted $y$ in place of pure mercury at $T_{2}=460^{\circ} \mathrm{C}$.

2.2 CHARACTERIZATION. - Electric contacts are obtained by an electrolytic deposition of $\mathrm{Ni}$, followed by an $\mathrm{Au}$ one. $50 \mu \mathrm{m}$ diameter gold wires are then soldered using an In-Pb-Bi alloy giving low thermovoltage and low temperature fusion point. These contacts remain ohmic down to $4.2 \mathrm{~K}$, both on $\mathrm{p}$ or $\mathrm{n}$ type samples.

Electrical measurements are made in the Van der Pauw configuration. First they are monitored in a conventional magnet giving magnetic fields up to 1 Tesla, in a cryostat allowing $77 \mathrm{~K}-300 \mathrm{~K}$ temperature variations, with a good stability. Good samples are then choosen and new measurements are made between $4 \mathrm{~K}$ and $300 \mathrm{~K}$ using a superconducting magnet where the induction reaches 4 Teslas.

An automatic monitoring system followed by a microcomputer treatment allows data acquisition for each $B$ and $T$ value. Calculations give resistivity $(\rho)$ and Hall coefficient $\left(R_{\mathrm{H}}\right)$ variations with temperature and magnetic field.

\section{Experimental results on p-type samples.}

3.1 AS-GROWN SAMPLES. - The resistivity value remains approximatly constant in the $100 \mathrm{~K}-300 \mathrm{~K}$ range (Fig. 1) about $10^{-3}$ S.m ; a sharp increase appears at lower temperatures; $\rho$ goes up to $10^{-1} \Omega . \mathrm{m}$ at $4.2 \mathrm{~K}$. To explain these results it is necessary to study carrier concentrations and mobilities variations with temperature.

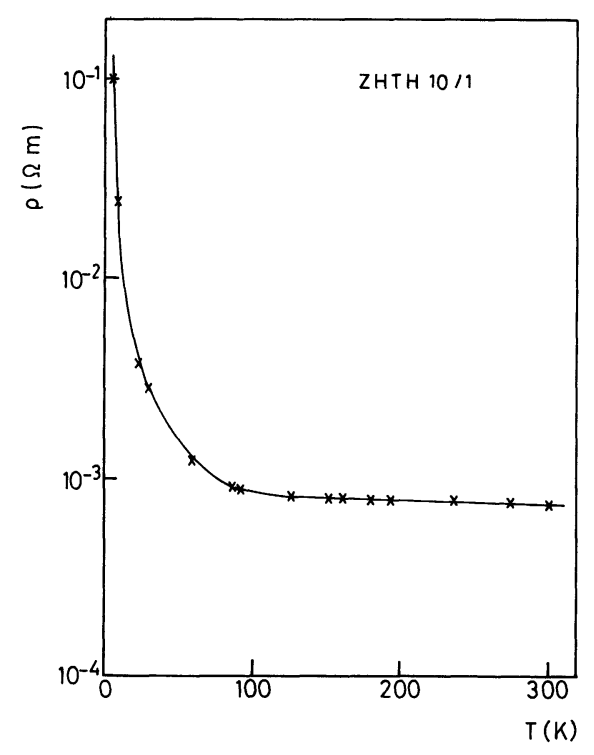

Fig. 1. - Temperature dependence of electrical resistivity on an as-grown sample.

Typical $R_{\mathrm{H}}$ variations with temperature are shown in figure 2 for magnetic field $B=0.1 \mathrm{~T}$ and $1 \mathrm{~T}$. The change of $R_{\mathrm{H}}$ sign with temperature depends on the magnetic field. This indicates a mixed conduction, as expected in small gap semiconductors $(x=0.15)$

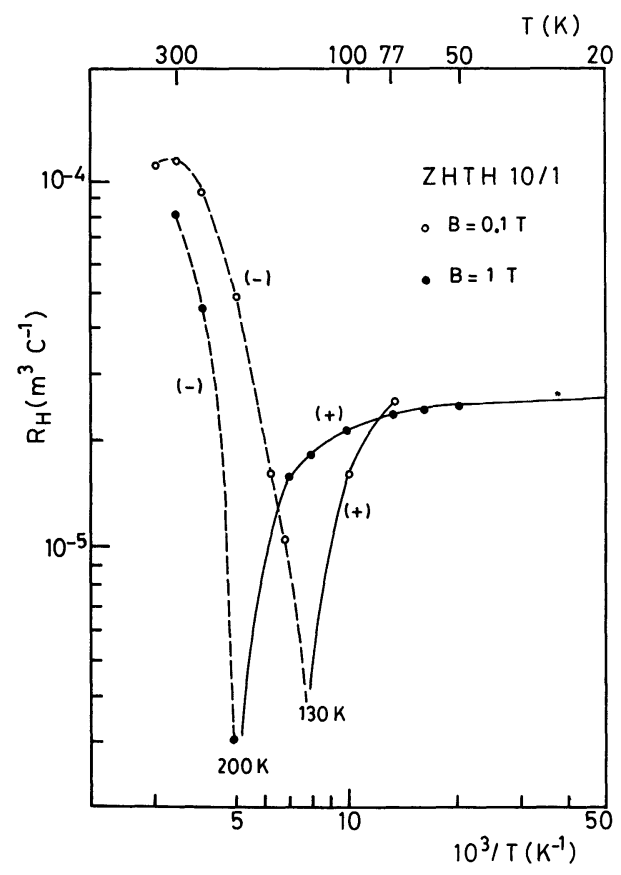

Fig. 2. - Temperature dependence of Hall coefficient at two magnetic fields : (+) means $R_{\mathrm{H}}$ positive ; (-) $R_{\mathrm{H}}$ negative. 
where the intrinsic concentration at $300 \mathrm{~K}$ is in the range of $10^{16} \mathrm{~cm}^{-3}$. The mixed range depends of course on the hole concentration $p$. Given a $p$ value, it appears a plateau on the $R_{\mathrm{H}}$ curves versus $T$ at low temperature. This plateau allows to determine the extrinsic hole concentration $p_{0}$ as shown in figure 3 from the usual formula $R_{\mathrm{H}}=\frac{1}{p_{0} e}$ assuming a diffusion factor equal to 1 . The increase of $\boldsymbol{R}_{\mathrm{H}}$ at lower temperatures is attributed to the ionization of an acceptor whose characterization is not studied here.

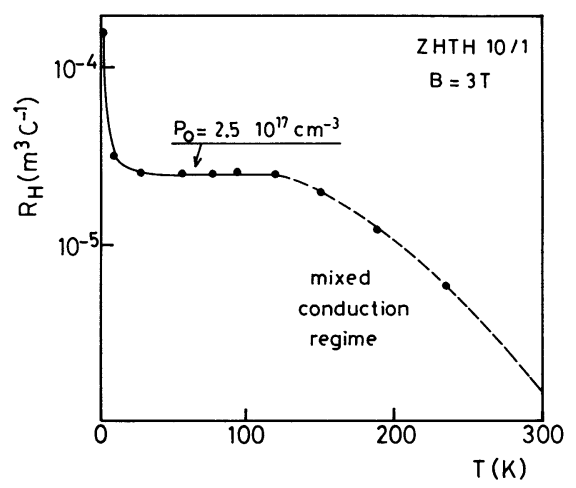

Fig. 3. $-p_{0}$ determination from curve $R_{\mathrm{H}}(T)$ at $B=3 \mathrm{~T}$; in doted line mixed conduction regime.

When temperature increases, intrinsic electrons appear and calculations in the mixed conduction range are done using the assumptions of spherical energy bands, parabolicity and energy independent relaxation time [10]. With these assumptions :

$$
R_{\mathrm{H}}=\frac{1}{e} \frac{p \mu_{\mathrm{p}}^{2}-n \mu_{\mathrm{n}}^{2}+\mu_{\mathrm{p}}^{2} \mu_{\mathrm{n}}^{2} B^{2}(p-n)}{\left(p \mu_{\mathrm{p}}+n \mu_{\mathrm{n}}\right)^{2}+\mu_{\mathrm{p}}^{2} \mu_{\mathrm{n}}^{2} B^{2}(p-n)^{2}}
$$

$p$ and $n$ are respectively the hole and electron concentrations, $\mu_{\mathrm{p}}$ and $\mu_{\mathrm{n}}$ their mobilities. Moreover $\sigma=e\left(p \mu_{\mathrm{p}}+n \mu_{\mathrm{n}}\right)$ and $p_{0}=p-n$ corresponding to charge conservation. Resolution of such equations needs $\sigma, p_{0}$ and two $R_{\mathrm{H}}$ values obtained at two different magnetic fields. Solving the four equations using Newton method, gives $p, \mu_{\mathrm{p}}, n$, $\mu_{n}$ at each temperature in the mixed conduction range. The intrinsic electron concentration $n_{\mathrm{i}}$ is then deduced by $n_{\mathrm{i}}^{2}=n \cdot p$. Assuming $n_{\mathrm{i}}$ proportional to $T^{3 / 2} e^{-E_{\mathrm{g}} / 2 k T}$, where $E_{\mathrm{g}}$ is the band gap energy at $T=0 \mathrm{~K}$, a plot of $n_{\mathrm{i}} / T^{3 / 2}$ as a function of $\frac{1}{T}$ (Fig. 4) gives the $E_{\mathrm{g}}$ value from the linear part of the curve. The linear gap variation with temperature assumed here has been verified down to $50 \mathrm{~K}$ [6]. The $E_{\mathrm{g}}$ values so deduced are compared with those obtained by optical measurements [6]. From the $E_{\mathrm{g}}$ value, we obtain the $x$ composition of the samples. A very fine agreement is found between

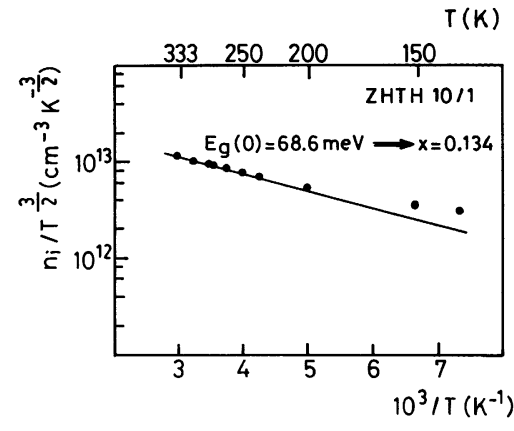

Fig. 4. $-n_{\mathrm{i}} / T^{-3 / 2}$ versus $1000 / T$.

the $x$ determination through $n_{\mathrm{i}}$ and $\langle x\rangle$ measured by microprobe analysis [11] (Tab. I) in view of composition inhomogeneity.

Table I. - Characteristics of as grown samples: $p_{0}$ extrinsic concentration; $n_{\mathrm{i}}$ intrinsic concentration at $300 \mathrm{~K} ; E_{\mathrm{g}}(0 \mathrm{~K})$ energy gap; $x$ calculated composition (Cf. Sect. 3.1); $\langle x\rangle$ mean value obtained from microprobe analysis; $x_{\min }$ and $x_{\max }$, extrema of these measurements.

\begin{tabular}{|c|c|c|c|c|c|c|c|}
\hline Sample & $\begin{array}{c}\mathrm{P}_{\circ} \\
\left(\mathrm{cm}^{-3}\right)\end{array}$ & $\begin{array}{c}n_{i} \\
\left(\mathrm{~cm}^{-3}\right)\end{array}$ & $\begin{array}{l}E_{g}(0) \\
(m e V)\end{array}$ & $\begin{array}{c}x \\
\text { calculated }\end{array}$ & $\langle x\rangle$ & $x \min i$ & $x_{\text {max }}$ \\
\hline ZHTH $10 / 1$ & $2.510^{17}$ & $2.9310^{16}$ & 68 & 0.132 & 0.137 & 0.126 & 0.146 \\
\hline ZHTH $14 / 1$ & $5.110^{17}$ & $2.5710^{16}$ & 117 & 0.145 & 0.157 & 0.145 & 0.169 \\
\hline ZHTH $27 / 11$ & $21 \quad 10^{17}$ & $5.2710^{16}$ & 47 & 0.126 & 0.124 & 0.112 & 0.139 \\
\hline ZHTM $11 / 2$ & $5.610^{17}$ & $2.0410^{16}$ & 111 & 0.150 & 0.160 & 0.151 & 0.170 \\
\hline ZHTM $13 / 2$ & $5.2 \quad 10^{17}$ & $1.6310^{16}$ & 52 & 0.128 & 0.159 & 0.146 & 0.176 \\
\hline
\end{tabular}

However carrier concentration evaluations in the mixed regime are limited in the temperature range $200 \mathrm{~K}-300 \mathrm{~K}$. Below $200 \mathrm{~K}$, the intrinsic concentration is too small and the method gives significant errors (See Fig. 4).

At low temperatures, as shown in figure 3, $R_{\mathrm{H}}$ increases rapidly. The hole concentration decreases and $\mu_{\mathrm{p}}$ remains approximatly constant [5], this explains the increase of resistivity at $4.2 \mathrm{~K}$.

In table II, results obtained on as-grown samples issued from two ingots ZHTH and ZHTM are shown. In the first ZHTH ingot, $p_{0}$ increases from the beginning of the ingot ( $\mathrm{ZHTH} \mathrm{8/1)}$ to the end with a stronger variation at the end of the ingot (ZHTH 27/3). This $p_{0}$ concentration is correlated to the longitudinal $x$ composition [3]. The hole concentration appears more homogeneous in the second ingot where $p_{0} \simeq 6 \times 10^{17} \mathrm{~cm}^{-3}$.

3.2 ANNEAled SAMPLES. - First annealings were made with $T_{1}=400^{\circ} \mathrm{C}$ and $T_{2}=380^{\circ} \mathrm{C}$ during $114 \mathrm{~h}$. Results of concentrations and mobilities at $77 \mathrm{~K}$ and $300 \mathrm{~K}$ are shown in table III. An equilibrium state is reached with $p_{0} \simeq 1.2 \times 10^{17} \mathrm{~cm}^{-3}$. New 
Table II. - Electronic properties of as-grown samples : 2 A ZHTH ingot, 2 B ZHTM ingot.

\begin{tabular}{|c|c|c|c|c|}
\hline \multirow{2}{*}{ Sample } & $\begin{array}{c}\mathrm{P}_{\mathrm{o}} \\
\left(10^{17} \mathrm{~cm}^{-3}\right)\end{array}$ & \multicolumn{2}{|c|}{$\mu_{\mathrm{p}}\left(\mathrm{cm}^{2} / \mathrm{V} . \mathrm{s}\right)$} & $\mu_{\mathrm{n}}\left(\mathrm{cm}^{2} / \mathrm{V} . \mathrm{s}\right)$ \\
\hline ZHTH $8 / 1$ & 1.8 & 268 & $77 \mathrm{~K}$ & $(290 \mathrm{~K})$ \\
ZHTH 10/1 & 2.5 & 262 & 308 & 8160 \\
ZHTH 14/1 & 5.1 & 208 & 205 & 7400 \\
ZHTH 23/13 & 26 & 102 & 129 & 11440 \\
ZHTH 23/33 & 26 & 112 & 140 & 11920 \\
ZHTH 27/11 & 21 & 108 & 127 & 9880 \\
\hline
\end{tabular}

\begin{tabular}{|c|c|c|c|c|}
\hline \multirow{2}{*}{ Sample } & $\mathrm{P}_{\mathrm{o}}$ & \multicolumn{2}{|c|}{$\mu_{\mathrm{p}}\left(\mathrm{cm}^{2} / \mathrm{V} \mathrm{s}\right)$} & $\mu_{\mathrm{n}}\left(\mathrm{cm}^{2} / \mathrm{V} \mathrm{s}\right)$ \\
\cline { 3 - 4 } & $\left(10^{17} \mathrm{~cm}^{-3}\right)$ & $290 \mathrm{~K}$ & $77 \mathrm{~K}$ & $(290 \mathrm{~K})$ \\
\hline ZHTM 11/2 & 5.6 & 136 & 204 & 7500 \\
ZHTM 12/2 & 6.7 & 121 & 180 & 6316 \\
ZHTM 13/2 & 5.2 & 155 & 200 & 10548 \\
ZHTM 14/2 & 6.7 & - & 160 & - \\
ZHTM 15/1 & 5.0 & 161 & 231 & 7200 \\
\hline
\end{tabular}

Table III. - Electronic properties after annealing with $T_{1}=400{ }^{\circ} \mathrm{C}, T_{2}=380^{\circ} \mathrm{C}$.

\begin{tabular}{|c|c|c|c|c|c|}
\hline \multirow{2}{*}{ Sample } & \multirow{2}{*}{$\begin{array}{l}\text { Annealing } \\
\text { time(hours }\end{array}$} & \multirow{2}{*}{$\begin{array}{c}P_{\circ} \\
\left(10^{17} \mathrm{~cm}^{-3}\right)\end{array}$} & \multicolumn{2}{|c|}{$\mu_{p}\left(\mathrm{~cm}^{2} / \mathrm{V} \cdot \mathrm{s}\right)$} & \multirow{2}{*}{$\begin{array}{c}\mu_{n}\left(\mathrm{~cm}^{2} / \mathrm{V} . \mathrm{s}\right) \\
(290 \mathrm{~K})\end{array}$} \\
\hline & & & $290 \mathrm{~K}$ & $77 \mathrm{~K}$ & \\
\hline $\mathrm{ZHTH} 8 / 5$ & 114 & 0.35 & 505 & 316 & 11820 \\
\hline ZHTH $14 / 5$ & 114 & 1.4 & 154 & 162 & 8990 \\
\hline ZH TH $27 / 3$ & 114 & 1.25 & 395 & 417 & 10800 \\
\hline ZHTM $13 / 3$ & 237 & 1.2 & 330 & 231 & 11038 \\
\hline ZHTM $10 / 1$ & 237 & 1.16 & 240 & 373 & 8709 \\
\hline
\end{tabular}

annealings in order to control $p_{0}$ with $\mathrm{Hg}$ pressure are performed changing $T_{2} . T_{1}=500^{\circ} \mathrm{C}$ has been next choosen to get a higher diffusion rate of the species and then, shorter annealing times to equilibrate samples.

According to Vydyanath results [12] in MCT case (with $x=0.2$ corresponding to the same band gap as MZT with $x=0.15), p_{0}$ would change with a $P_{\mathrm{Hg}}^{-1}$ law, $P_{\mathrm{Hg}}$ being the mercury partial pressure. Acceptor centers are doubly ionized mercury vacancies. At high mercury pressure : $T_{2}=460^{\circ} \mathrm{C}$, the $P_{\mathrm{Hg}}$ high value limit the vacancies concentration and then $p_{0}$. When $T_{2}$ is smaller (for example $350{ }^{\circ} \mathrm{C}$ ) this number will increase and we can expect higher $p_{0}$.

In table IV and $V$ results are shown for these two $T_{2}$ temperatures. For $T_{2}=460^{\circ} \mathrm{C}$, this corresponds to a mercury vapor pressure of 3.5 atmospheres and the resulting $p_{0}$ is $5 \times 10^{17} \mathrm{~cm}^{-3}$. For $T_{2}=350{ }^{\circ} \mathrm{C}$, $P_{\mathrm{Hg}}=1$ atmosphere and $p_{0}=1.9 \times 10^{18} \mathrm{~cm}^{-3}$. These first results of $p_{0}$ versus $\boldsymbol{P}_{\mathrm{Hg}}$ for MZT are
Table IV. - Electronic properties after annealing with $T_{1}=500{ }^{\circ} \mathrm{C}, T_{2}=460{ }^{\circ} \mathrm{C}$.

\begin{tabular}{|c|c|c|c|c|c|}
\hline \multirow{2}{*}{ Sample } & Annealing & $P_{0}$ & \multicolumn{2}{|c|}{$\mu_{\mathrm{p}}\left(\mathrm{cm}^{2} / \mathrm{V} . \mathrm{s}\right)$} & $\mu_{n}\left(\mathrm{~cm}^{2} / \mathrm{V} . \mathrm{s}\right)$ \\
\cline { 4 - 5 } & time(hours $)$ & $\left(10^{17} \mathrm{~cm}^{-3}\right)$ & $290 \mathrm{~K}$ & $77 \mathrm{~K}$ & $(290 \mathrm{~K})$ \\
\hline ZHTH 10/23 & 384 & 3.6 & 224 & 246 & 8365 \\
ZHTM 13/4 & $96^{*}$ & 5.2 & 180 & 186 & 7094 \\
ZHTM 14/4 & 96 & 6 & 150 & 169 & 7190 \\
ZHTM 14/12 & 96 & 5.6 & 145 & 159 & 7158 \\
ZHTM 14/3 & $96 *$ & 5.18 & 130 & 171 & 8389 \\
\hline
\end{tabular}
* Previously annealed at $400 / 380^{\circ} \mathrm{C}$ during $237 \mathrm{~h}$

Table V. - Electronic properties after annealing with $T_{1}=500{ }^{\circ} \mathrm{C}, T_{2}=350^{\circ} \mathrm{C}$.

\begin{tabular}{|c|c|c|c|c|c|}
\hline \multirow{2}{*}{ Sample } & \multirow{2}{*}{$\begin{array}{c}\text { Annealing } \\
\text { time(hours) }\end{array}$} & $\begin{array}{c}\mathrm{P}_{\mathrm{o}} \\
\left(10^{17} \mathrm{~cm}^{-3}\right)\end{array}$ & \multicolumn{2}{|c|}{$\mu_{\mathrm{p}}\left(\mathrm{cm}^{2} / \mathrm{V} . \mathrm{s}\right)$} & $\mu_{n}\left(\mathrm{~cm}^{2} / \mathrm{V} . \mathrm{s}\right)$ \\
\cline { 4 - 5 } & & $190 \mathrm{~K}$ & $77 \mathrm{~K}$ & $(290 \mathrm{~K})$ \\
\hline ZHTH 8/5 & 136 & 19 & 104 & 110 & 8250 \\
ZHTM 15/4 & 111 & 11 & 130 & 121 & 6140 \\
\hline
\end{tabular}

reported in figure 5 with those of Vydyanath [12] for comparison. The $P_{\mathrm{Hg}}^{-1}$ law appears verified like in MCT so the same defect model may be applied. Nevertheless the $p_{0}$ values are higher in MZT. A detailed investigation with different $T_{1}$ and $T_{2}$ temperatures is necessary and currently performed in order to obtain the mass action law constants.

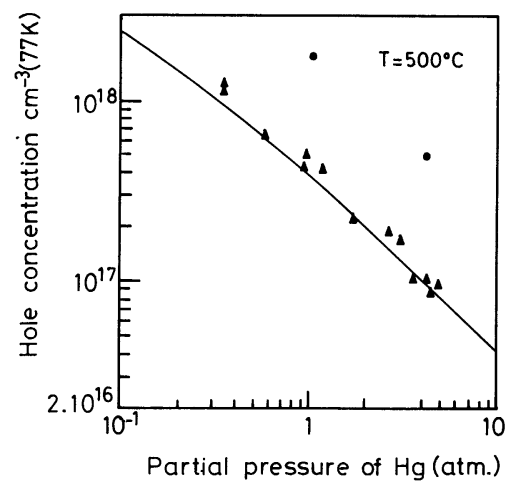

Fig. 5. $-p_{0}$ variations with mercury partial pressure: $(\boldsymbol{\Lambda}): \mathrm{Hg}_{1-x} \mathrm{Cd}_{x} \mathrm{Te}$ case [12] ; $(\bullet)$ : our results.

\section{4. $p$ to n-type change.}

4.1 STCECHOMETRIC ANNEALING. - Considering that concentration $p_{0}$ decreases when the annealing temperature $T_{1}$ decreases, annealings were made with $T_{1}=260^{\circ} \mathrm{C}$ and $T_{2}=240^{\circ} \mathrm{C}$. In the MCT case, this gives n-type homogeneous samples. But on MZT as-grown samples, only an n-type surface layer appears. Its thickness, as given by thermoelectric probing, follows a $\sqrt{t}$ law, $t$ being the annealing time (Fig. 6). From these measurements, a diffusion 


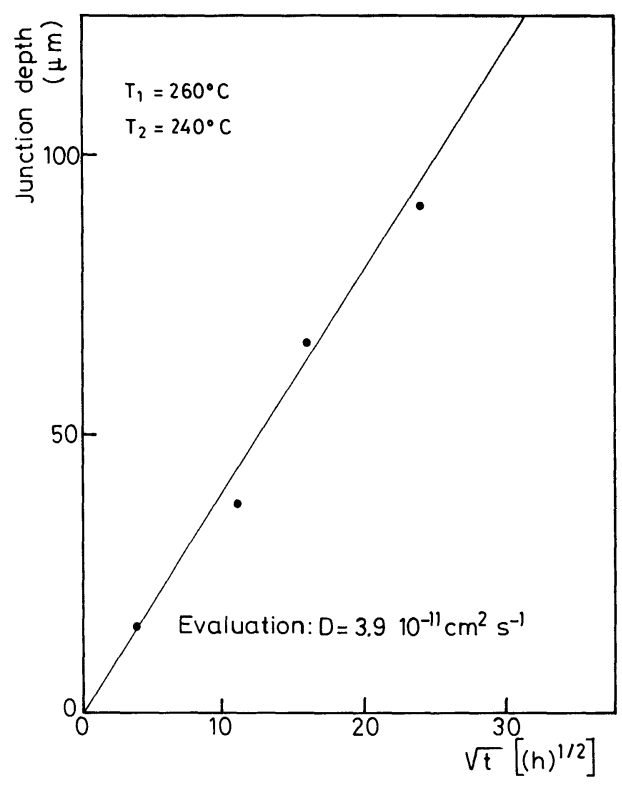

Fig. 6. - n-p front depth versus the root square of annealing time for $T_{1}=260^{\circ} \mathrm{C}$ and $T_{2}=240{ }^{\circ} \mathrm{C}$.

coefficient for $\mathrm{p}$ to $\mathrm{n}$-type change has been estimated to be $D=3.9 \times 10^{-11} \mathrm{~cm}^{2} \cdot \mathrm{s}^{-1}$. With this value of $D$ it is necessary to anneal during about 200 days a one mm thick sample to have an $\mathrm{n}$ homogeneous sample.

At the present time, a complete understanding of $\mathrm{p}$ to $\mathrm{n}$-type conversion mechanism is not available in MCT. It is commonly assumed that annealing with mercury overpressure fills mercury vacancies which are acceptors and the conversion to n-type results from residual donor impurities ; but donors due to interstitial mercury cannot be ruled out [13]. The situation is also complicated by the presence of excess tellurium, likely precipitates, and unknown residual acceptor impurities. The same problems are of course encountered in MZT. In order to test the influence of Tellurium precipitates in MZT, we have performed a preliminary long time annealing with $T_{1}=400^{\circ} \mathrm{C}$ and $T_{2}=380^{\circ} \mathrm{C}$, followed by a low temperature annealing with $T_{1}=260^{\circ} \mathrm{C}$, $T_{2}=240^{\circ} \mathrm{C}$ during 4 hours. The thickness deduced from thermoelectric probing was about $30 \mu \mathrm{m}$ (Fig. 7) giving a diffusion coefficient of $4.3 \times$ $10^{-10} \mathrm{~cm}^{2} \cdot \mathrm{s}^{-1}$, which is about ten times higher than the first given value. These results are near those of Harman in MCT [13] and can be explained by a dissolution of tellurium precipitates after a high temperature annealing. Nevertheless the diffusion coefficient remains smaller in MZT.

Subsequent low temperature annealing has been then performed during the very long time of 430 hours in order to obtain an n-type homogeneous sample. The sample was homogeneous but p-type, as shown in figure 7 . Such results have been obtained in MCT [14] and the explanation remains the same.

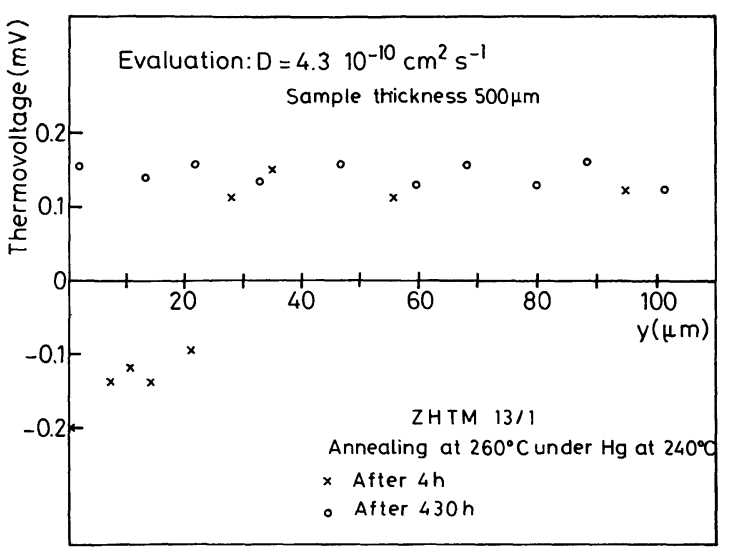

Fig. 7. - Thermoelectric signal versus position, after annealing at $260^{\circ} \mathrm{C}-240{ }^{\circ} \mathrm{C}:(x)$ after $4 \mathrm{~h} ;(0)$ after $430 \mathrm{~h}$. The sample was previously annealed at $400{ }^{\circ} \mathrm{C}-380^{\circ} \mathrm{C}$ during $96 \mathrm{~h}$.

Excess tellurium in the material dissolves a high concentration of acceptor impurities. As the annealed $n$ part progresses from the surface of the sample, this excess of tellerium disappears and releases its solved impurities. These ones fast diffuse through the matrix under their induced concentration gradient toward the core of the sample where they are gettered. For a long enough annealing time all tellurium in excess is removed over all the sample leading to a uniform redistribution of these impurities.

The residual acceptor concentration appears to be higher in the samples than the donor one. The acceptors come probably from the starting $\mathrm{Zn}$ which is not of electronic grade. Refining processes are currently carried out to overcome this difficulty which is not dramatic for device elaboration when keeping a p-type core [15] but critical for material characterization.

Concentration $n$ and mobility of electrons in the $n$ layer are deduced from electrical measurements and its thickness using the model of Petritz [16] in a two-

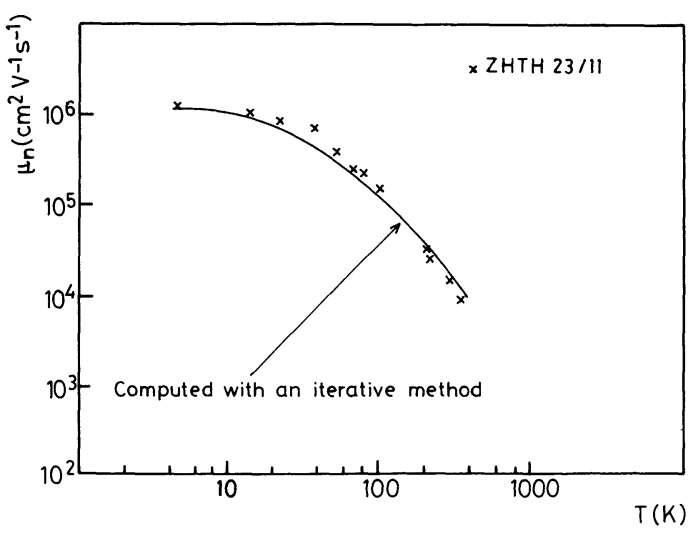

Fig. 8. - Temperature variation of electron mobility : $(\times)$ experimental results ; $(-)$ calculated curve by an iterative method. 
layer model. $n$ is about $10^{16} \mathrm{~cm}^{-3}$ and mobility variations with temperature appear in figure 8 . Theoretical calculations describing these variations are presented in the part 5.

4.2 VAPOR PHASE INDIUM DOPED SAMPLES. Doping by In is done through vapor phase. Annealings with $T_{1}=500^{\circ} \mathrm{C}$ and $T_{2}=460{ }^{\circ} \mathrm{C}$ are performed during 104 hours, with an $\mathrm{Hg}$-In (50/50) alloy at temperature $T_{2}$. By thermoelectric probing at room temperature, and n-type layer of $70 \mu \mathrm{m}$ thickness is found (Fig. 9). The value of the estimated diffusion coefficient is $8.3 \times 10^{-11} \mathrm{~cm}^{-2} \cdot \mathrm{s}^{-1}$ which is ten times the corresponding value found in MCT at $500^{\circ} \mathrm{C}$ after In implantation [17].

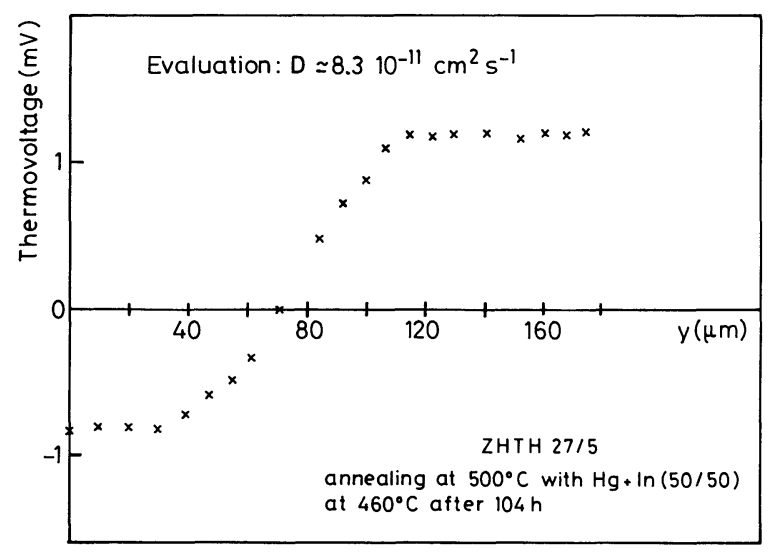

Fig. 9. - Thermoelectric signal versus position, on indium doped sample.

For these samples $R_{\mathrm{H}}$ is constant with magnetic field ; its variations with $T$ are presented in figure 10 , the corresponding electron concentration is $1.85 \times$ $10^{18} \mathrm{~cm}^{-3}$. The electron mobility is low (Fig. 11) reaching only $4 \times 10^{3} \mathrm{~cm}^{2} / \mathrm{V}$.s at $4.2 \mathrm{~K}$ instead of the $10^{6} \mathrm{~cm}^{2} / \mathrm{V}$.s value found after a stœechiometric annealing. As shown by Vydyanath [18] in MCT for $x=0.2$, only a few percent of indium gives donor

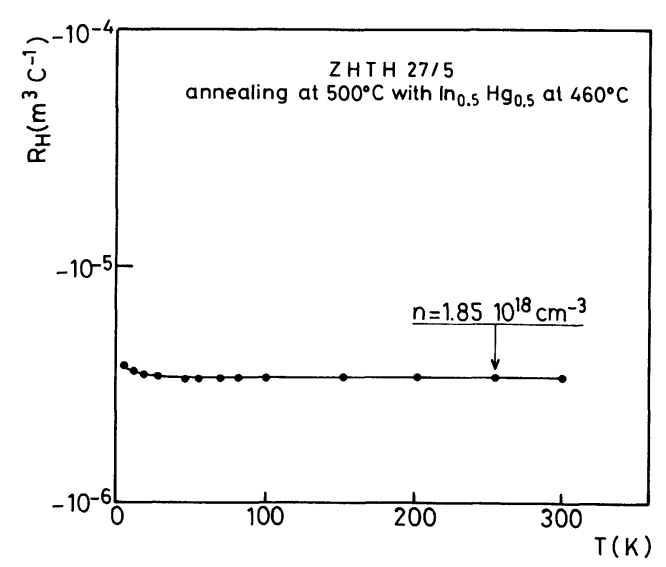

Fig. 10. $-R_{\mathrm{H}}$ variation with $T$ on indium doped sample.

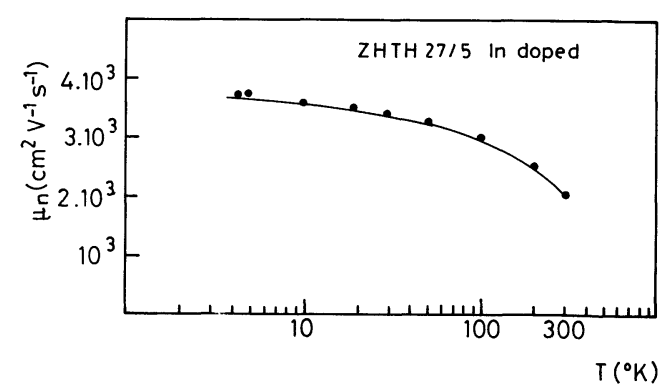

Fig. 11. - Electron mobility versus temperature on indium doped sample.

centers, the remainder, which remains neutral, limits the electron mobility due to supplementary scattering interaction (neutral impurity or core scattering).

\section{Discussion.}

5.1 ElECTRON MOBILITY. - Electron mobility results deduced from the mixed conduction range described in section 2 can be obtained only in the temperature range $200-300 \mathrm{~K}$. Their values vary between $12000 \mathrm{~cm}^{2} / \mathrm{V}$.s and $6000 \mathrm{~cm}^{2} / \mathrm{V}$.s at $300 \mathrm{~K}$ and do not appear correlated with hole concentration $p_{0}$.

From layered samples, n-type mobilities were obtained in the range $4.2 \mathrm{~K}-300 \mathrm{~K}$ (see Fig. 8). Electron mobility has been calculated using an iterative method to solve the Boltzman transport equation in the two band Kane model $[19,20,5]$. A great number of the necessary parameters are presently unknown. A linear interpolation of their values for the binaries $\mathrm{HgTe}$ and $\mathrm{ZnTe}$ is tentatively done [5].

Moreover, the k·p matrix element $\boldsymbol{P}_{\mathrm{cv}}$ and the spin orbit coupling $\Delta$ values have been taken the same as for MCT [21, 22]. With these assumptions, calculated results (Fig. 8) agree with experimental ones, if we consider optical and acoustical phonon scattering, ionized impurity scattering, disordered alloy scattering with a core radius of $r_{0}=2 \AA$ and a scattering center concentration of $2 \times 10^{21} \mathrm{~cm}^{-3}$ [5]. Nevertheless, in the lack of knowledge of band edge effective mass for electrons, it is not usefull to go deeper in the scattering mechanisms any longer.

For n-type indium doped samples, we find only mobilities up to $4000 \mathrm{~cm}^{2} /$ V.s. This agrees with results in MCT of similar n-type concentrations [17, $18]$ : only low fraction of indium in the matrix would give a donor state.

5.2 HOLE MOBILITY. - Hole mobilities versus temperature are show in figure 12 between $77 \mathrm{~K}$ and $300 \mathrm{~K}$ for different $p_{0}$ values which reveals a decrease of mobility when $p_{0}$ increases. More significantly figure 13 and figure 14 show the hole mobilities at 


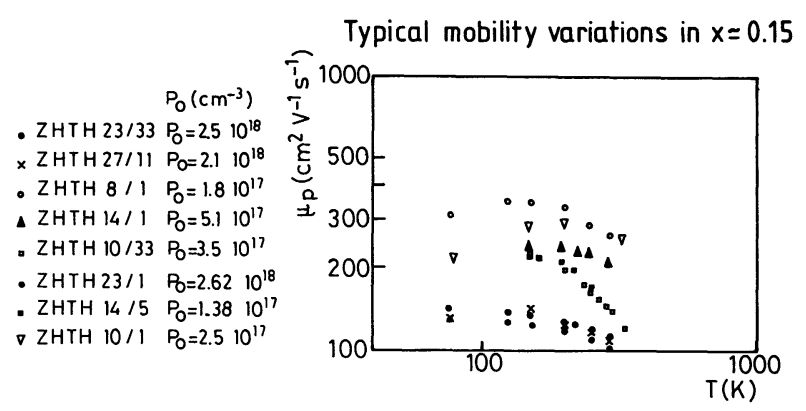

Fig. 12. - Temperature dependence of hole mobility for several samples.

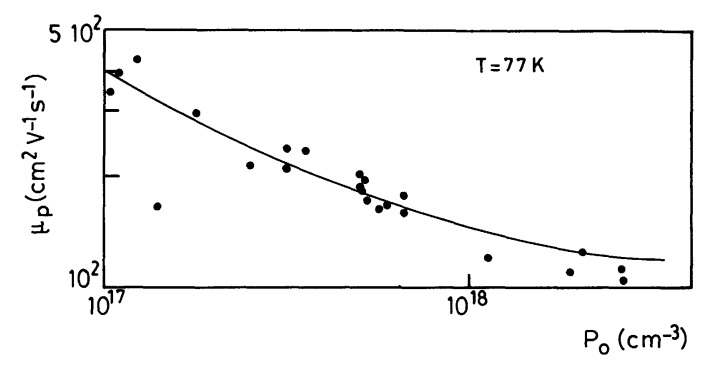

Fig. 13. - Hole mobility variations with $p_{0}$ at $77 \mathrm{~K}$. Experimental results on MZT, solid curve : results on MCT [12].

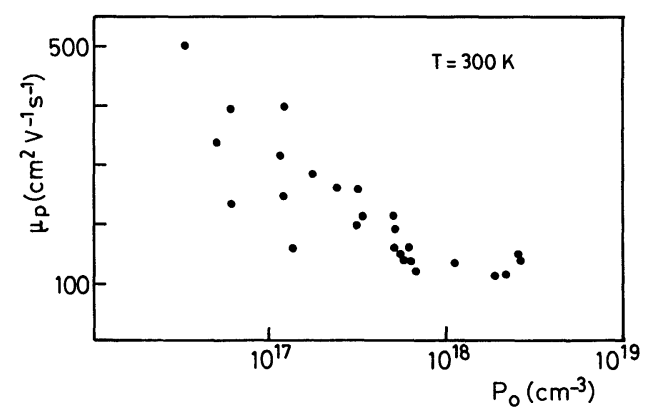

Fig. 14. - Hole mobility variations with $p_{0}$ at $300 \mathrm{~K}$.

$77 \mathrm{~K}$ and $300 \mathrm{~K}$. At $77 \mathrm{~K}$, the behaviour is very similar to MCT one, where Vydyanath deduced it is due to doubly ionized acceptors [18]. Although it is presumably the same in MZT, we have not yet got sufficient informations to conclude ; specially, doping by acceptor impurities like copper is necessary. At this stage of knowledge it is more difficult to evaluate the hole mobility since too much band parameters are necessary.

At $300 \mathrm{~K}$, the strong decrease of mobility for higher $p_{0}$ cannot be explained by usual scattering mechanisms. It would be necessary to introduce others scattering processes to describe the actual values.

5.3 INTRINSIC CARRIER CONCENTRATION AT $300 \mathrm{~K} .-n_{\mathrm{i}}$ is deduced from $p$ and $n$ concentrations values $\left(n \cdot p=n_{\mathrm{i}}^{2}\right)$. These $300 \mathrm{~K}$ values versus the sample mean composition $\langle x\rangle$ are presented in figure $15 ;\langle x\rangle$ measurements are taken on samples used for electrical measurements or neighbour samples by electronic microprobing [11]. Examples of $\langle x\rangle$ and $n_{\mathrm{i}}$ values appear in table $\mathrm{I}$.

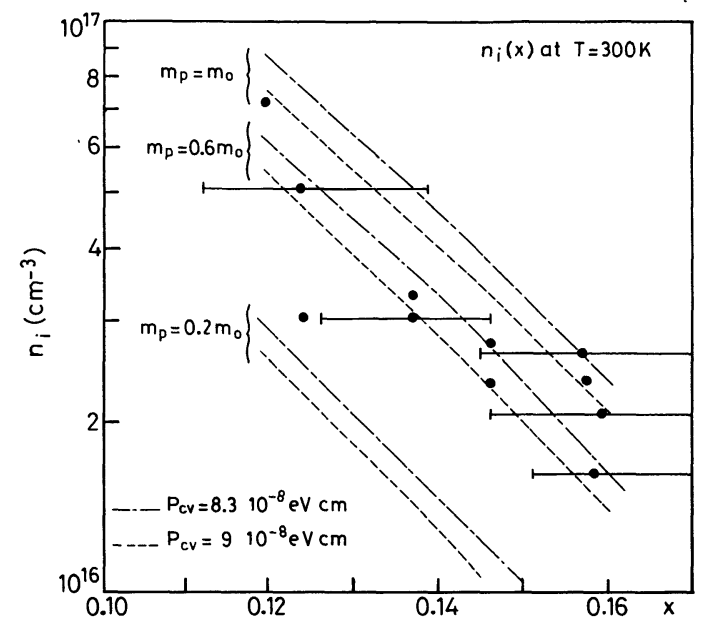

Fig. 15. - Intrinsic concentration $n_{\mathrm{i}}$ versus $x$ composition : $(\bullet)$ : experimental determination from section 3.1. The bars indicate incertitudes on $x$ composition as seen in table I. Curves are calculated using Kane model with two values of matrix element $P_{\mathrm{cv}}$ and three values of hole effective mass.

In order to calculate $n_{\mathrm{i}}$, the following step is used : $x$ and $T$ being choosen, $E_{\mathrm{g}}(x, T)$ is obtained from [6]. A test value for the electron concentration is taken; then the Fermi energy $E_{\mathrm{F}}$ is deduced with a non parabolic conduction band using the Kane model [23]. The hole concentration corresponding to this $E_{\mathrm{F}}$ value is calculated with the Fermi Dirac statistics and a parabolic heavy hole band. The heavy hole effective mass $m_{\mathrm{p}}$ is taken as a parameter and the light hole valence band is omitted. An iterative process gives the $n$ value corresponding to $n=p=n_{\mathrm{i}}$. Calculations were performed at $300 \mathrm{~K}$ for three $m_{\mathrm{p}}$ values : $m_{\mathrm{p}}=0.2 m_{0}, m_{\mathrm{p}}=0.6 m_{0}$ and $m_{0}$. The Kane matrix element $P_{\mathrm{cv}}$ is almost constant in II-VI compounds [21], [24-30]. The extrem values reported $P_{\mathrm{cv}}=9 \times 10^{-8} \mathrm{eV} . \mathrm{cm}$ and $P_{\mathrm{cv}}=8.3 \times$ $10^{-8} \mathrm{eV} . \mathrm{cm}$ have been used for each $m_{\mathrm{p}}$ value. The curves are drawn in figure 15 and compared with data deduced from experiments. A good fit is obtained for $m_{\mathrm{p}}=0.6 m_{0}$. The incertitudes on experimental $x$ values do not allow a more precise parameters determination.

\section{Conclusion.}

First reliable results on carrier concentration and mobility of $\mathrm{Hg}_{1-x} \mathrm{Zn}_{x}$ Te for $x=0.15$ after annealing under mercury pressure are presented. Samples remain p-type for annealing temperature above 
$300{ }^{\circ} \mathrm{C}$ : their concentration depends on mercury pressure. At lower temperature $\left(T=260^{\circ} \mathrm{C}\right)$ it is possible to convert p-type to n-type by annealing under mercury pressure (stoichiometric annealing) which decreases mercury vacancies.

The kinetics of this conversion is low compared to the corresponding one in $\mathrm{Hg}_{1-x} \mathrm{Cd}_{x} \mathrm{Te}$ for $x \simeq 0.2$ revealing a better stability of this material despite its higher mercury composition.

This kinetics is also controlled by the excess of tellurium present in samples. Moreover, the residual acceptor concentration appears higher than the donor one. This situation does not allow to obtain at the present time thick n-type homogeneous samples. n-type doping by indium suffers of a low diffusion coefficient and leads to a very low electron mobility.

In fact transport properties in MZT and MCT of the same band gap appear very near but this statement has to be better settled after a measure of the main band structure parameters. Nevertheless we can assert already now that MZT have electrical properties at least as suitables as the MCT ones for device elaboration, a definite advantage rising in its better stability.

\section{References}

[1] Sher A., Chen A. B., Spicer A. E. and Shih C. K., J. Vac. Sci. Technol. A3 (1985) 105.

[2] Sher A., Berding M. A., Chen A. B. and Patrick R. S., NATO Workshop, Liège, 1988, to be published.

[3] Triboulet R., Lasbley A., Toulouse B. and Granger R., J. Cryst. Growth 79 (1986) 695.

[4] Triboulet R., J. Cryst. Growth 86 (1988) 79.

[5] Granger R., Lasbley A., Rolland S., Pelletier C. M. and Triboulet R., J. Cryst. Growth 86 (1988) 682.

[6] Toulouse B., Granger R., Rolland S. and Triboulet R., J. Phys. France 48 (1987) 247.

[7] Triboulet R., Le Floch T. and Saulnier J., Proc. Conf. SPIE (Insbruck) Ed. J. Besson (1986) p. 150.

[8] Ameurlaine J., Rousseau A., Nguyen-Duy T. N. and TRIBOUlet R., Proc. SPIE ORLANDO (Floride) 1988, Unpublished.

[9] Triboulet R., Nguyen-Duy T. N. and Durand A., J. Vac. Sci. Technol. A 3 (1985) 95.

[10] SмIтH A., Semiconductors (Cambridge University Press) 1978, Chap. 5, p. 114.

[11] Measurements made at the West Microprobe Facility IFREMER, Brest. The $\mathrm{x}$ reported values are ten measurement averages.

[12] Vydyanath H. R., J. Electrochem. Soc 128 (1981) 2609.

[13] Harman J. C., J. Vac. Sci. Technol. 5 (1987) 3055.

[14] Tregilgass J., Beck J. and Gnade B., J. Vac. Sci. Technol. A 3 (1985) 150.
[15] Micklethwaite W. F. H., J. Appl. Phys. 63 (1988) 2382.

[16] Petritz R. L., Phys. Rev. 110 (1958) 1254.

[17] Destefanis G. L., J. Vac. Sci. Technol. A 3 (1985) 171.

[18] Vydyanath H. R., J. Electrochemi. Soc. 128 (1981) 2619.

[19] RodE D. L., Semiconductors and Semimetals, Ed. R. K. Willarson and A. C. Beer (Academic Press, New York) 1975, Chap. I.

[20] Lasbley A., Granger R., Pelletier C. M. and Rolland S., J. Phys. France 46 (1985) 1185.

[21] Mrozkowski J. A. and Nelson D. A., J. Appl. Phys. 54 (1983) 2041.

[22] Weiler M. H., Semiconductors and Semimetals, Ed. R. K. Willarson and A. C. Beer (Academic Press, New York) 1981, Vol. 16, p. 181.

[23] Zawadski W. and SzYmansKa W., Phys. Status Solidi (B) 45 (1971) 415.

[24] IVANov-OMSKII V. I., Kolomiets B. T., Malkova A. A. and Mekrtiev A. S., Phys. Status Solidi 32 (1909) K84.

[25] Lawaetz P., Phys. Rev. B 4 (1971) 3460.

[26] JedrzejCzaK A. and Dietl T., Phys. Status Solidi (B) 76 (1976) 737.

[27] Cardona M., J. Phys. Chem. Solids 24 (1963) 1543.

[28] Stradling R. A., Solid State Commun. 6 (1968) 665.

[29] Finkman E., J. Appl. Phys. 54 (1983) 1883.

[30] Schmit J. L., J. Appl. Phys. 41 (1970) 2876. 